\title{
Helicobacter pylori antibody patterns in Germany: a cross-sectional population study
}

\author{
Angelika Michel ${ }^{1 *}$, Michael Pawlita ${ }^{2}$, Heiner Boeing $^{3}$, Lutz Gissmann ${ }^{2}$ and Tim Waterboer $^{1}$
}

\begin{abstract}
Background: Helicobacter pylori infection that is usually acquired in childhood and lasts for lifetime is mostly asymptomatic but associated with severe gastrointestinal disease including cancer. During chronic infection, the gastric mucosa is histologically changing. This forces $\mathrm{H}$. pylori to permanent adaptation in its gastric habitat by expression of different proteins which might be reflected in distinctive antibody patterns.

Methods: To characterize dynamics of the immune response to $\mathrm{H}$. pylori we analysed 1797 sera of a cross-sectional study representative for the German population (age range 1-82 years) with multiplex serology, a fluorescent bead-based antibody binding assay that allows simultaneous and quantitative detection of antibodies. Fifteen recombinant, affinity-purified H. pylori proteins (UreA, GroEL, Catalase, NapA, CagA, CagM, Cag8, HP0231, VacA, HpaA, Cad, HyuA, Omp, HcpC and HP0305) were used as antigens.

Results: H. pylori seroprevalence (positivity for at least three antigens) was $48 \%$ and increased with age from $12 \%$ in children $<15$ years to $69 \%$ in females and $90 \%$ in males $>65$ years. Prevalences were highest ( $>83 \%)$ for Omp, VacA and GroEL. For 11 proteins, seroprevalence was higher in males than females $(P<0.05)$ from age 55 onwards. For all antigens, the median prevalence increase per age decade was stronger in males $(8.4 \%$, range 3.8-12.9\%) than females (6.1\%, range 3.4-10.8\%). However, among seropositives the median number of antigens recognized increased from children $<15$ years to individuals $>65$ years stronger in females $(P=0.02)$. Antibody reactivities to GroEL, HyuA, CagM, Catalase, NapA and UreA also increased stronger in females (average 1.7-fold/ decade, SD 0.5) than in males (1.5-fold/decade, SD 0.4).
\end{abstract}

Conclusion: H. pylori antibody response accumulates qualitatively and quantitatively with age. This may reflect a lifelong stimulation of the immune response by chronically active infection.

Keywords: Helicobacter pylori, Immune response, Bead-based multiplex serology

\section{Background}

More than half the world's middle-aged population is infected with the gram-negative bacterium Helicobacter pylori. Overall estimate of prevalence of infection is $78 \%$ in developing and $58 \%$ in developed countries [1]. Prevalence of infection steadily declines in the industrialized Western World and emerging economies [2]. The bacterium is ingested orally and is transmitted within families mostly by the mother [3,4]. H. pylori infection is acquired in childhood and if untreated persists lifelong as a chronically active infection [5]. Although the majority of infections

\footnotetext{
* Correspondence: A.Michel@dkfz.de

'Infections and Cancer Epidemiology (F020), Infection and Cancer Program, German Cancer Research Center (DKFZ), Im Neuenheimer Feld 280,

Heidelberg 69120, Germany

Full list of author information is available at the end of the article
}

are asymptomatic, the chronic inflammatory changes of the gastric mucosa hold the risk for serious diseases of the gastrointestinal tract. Clinical manifestations begin with acute gastritis, which in a fraction of cases evolves to chronic atrophic gastritis. Gastric ulcer develops in $10 \%$ of infected individuals, and gastric adenocarcinoma in $2 \%$ and rarely mucosa-associated lymphoid tissue (MALT) lymphoma is induced [6]. It is still under debate if and when to screen and whom to treat for $H$. pylori to reach maximum benefit [7,8]. For development of disease a permanent gastric inflammatory response to infection appears to be essential [9] and inflammation is enforced by a complex interplay of bacterial virulence factors, host cofactors (such as mediators of inflammation), genetic predispositions (such as IL-1ß polymorphisms), and dietary factors [10]. 
The $H$. pylori genome is of high plasticity and genomic changes such as recombination, mutation and uptake even of exogenous DNA modulate the interaction with the host and adapt the bacterium to environmental changes that occur with duration of infection and stage of disease $[10,11]$. These interactions with the host might change the complex immune response with age and might be reflected in specific antibody patterns which have so far rarely been investigated in the context of age and gender.

We have recently developed $H$. pylori multiplex serology [12]. In contrast to conventional serological diagnosis of infection, multiplex serology simultaneously quantifies antibodies directed against arrays of protein antigens [13]. Bacterially expressed, affinitypurified glutathione- $S$ transferase (GST) fusion proteins presenting conformational epitopes [14] are used as antigens. They are bound to individual sets of fluorescent polystyrene beads and antigen-loaded bead mixtures are exposed to human serum in a single reaction. For each bead set, antibodies bound to the respective antigen are quantified by streptavidin-R-phycoerythrin labelled monoclonal antibodies to human immunoglobulin. Multiplex serology allows analysis of 2000 sera per day for antibodies to up to 100 different antigens and thus provides a high-throughput platform for detection of antibody patterns in large epidemiological studies.

Using $H$. pylori multiplex serology [12], we have previously identified antibodies to HcpC and GroEL as new independent virulence factors that, in combination with the established markers anti-CagA and anti-VacA, were highly predictive of chronic atrophic gastritis risk [15]. We also found anti-CagA and anti-GroEL to be independent predictors of gastric cancer in a German case-control study [16]. Antibodies to all fifteen $H$. pylori proteins were associated with gastric cancer in a Swedish population-based cancer case-control study [17] and seropositivity to six proteins (Omp, HP305, HyuA, HpaA, CagA and VacA) may be a risk marker for distal gastric cancer in the high-incidence population of China [18].

To characterize the dynamics of the immune response as reflected in age and gender specific antibody patterns to fifteen different $H$. pylori proteins in a healthy population, we analysed 1,797 German individuals of a crosssectional study representative for the general population covering the range from 1-82 years of age [19] with $H$. pylori multiplex serology.

\section{Results}

$\mathrm{H}$. pylori antibody response in the German population We analysed the antibody response to fifteen $H$. pylori proteins, i.e. UreA, GroEL, Catalase, NapA, CagA, CagM, Cagא, HP0231, VacA, HpaA, Cad, HyuA, Omp, HcpC and HP0305 in 1,797 sera of the German population covering the range of 1 to 82 years of age (Table 1$)$. Overall $H$. pylori seroprevalence $(\mathrm{Hp}+)$, defined as antibody reactivity with at least four $H$. pylori proteins [12], was 48\% (Table 1).

Using predefined cut-off values for classification [12], $H$. pylori protein-specific antibody prevalence in all 1,797 sera was highest for Omp (54\%), GroEL (47\%) and VacA (46\%), lowest for Cad (15\%) and distributed between 25\% and 35\% for the other proteins (Table 2).

For each $H$. pylori protein, antibody prevalence was significantly higher in $\mathrm{Hp}+$ than in $\mathrm{Hp}$ - sera (all $P<0.0001$, Table 2). In $\mathrm{Hp}+$ sera, antibodies to Omp (88\%), GroEL (86\%) and VacA (83\%) were most prevalent. Antibodies to Cad (26\%) were least prevalent and ranged from $43 \%$ to $69 \%$ for the other eleven $H$. pylori proteins. In Hp- sera, reactions to Omp (23\%), UreA (16\%), Cag (13\%) and VacA (12\%) were most prevalent (Table 2).

\section{H. pylori seroprevalence varies by age and gender}

Overall $H$. pylori prevalence was similar for both genders with $48 \%$ in females and $49 \%$ in males. $\mathrm{Hp}+$ individuals were significantly older (median: 49 years) than $\mathrm{Hp}$ individuals (median: 29 years, $P<0.0001$ ). However, the $H$. pylori protein-specific seroprevalences depend strongly on age and gender.

$H$. pylori seroprevalence and $H$. pylori protein-specific prevalences were maximum in the oldest two age groups and increased significantly per age decade in males and females for all $H$. pylori proteins (all $P$ for trend $<0.0001$, Figure 1). Overall $H$. pylori seroprevalence rose more steeply in males ( $13.3 \%$ per decade) than in females (10.6\%) This corresponds to a mean prevalence increase per year of $1.2 \%$ for both genders. For all $H$. pylori proteins, the prevalence increase per age decade was stronger in males (median: $8.4 \%$, range: $3.8-12.9$ ) than in females (median: 6.1\%, range: 3.4-10.8), even when the oldest age group was excluded (males median: $7.5 \%$, range: 2.4-12.7; females median: 6.1\%, range: 3.4-11.4).

Table 1 Characteristics of the study population $(n=1797)$

\begin{tabular}{lcc}
\hline & & $\boldsymbol{n}(\%)$ \\
\hline Age $[$ years] & Male & $1040(57.9)$ \\
& $0-14$ & $757(42.1)$ \\
& $15-24$ & $187(10.4)$ \\
& $25-34$ & $235(13.1)$ \\
& $35-44$ & $377(21.0)$ \\
& $45-54$ & $278(15.5)$ \\
& $55-64$ & $281(15.6)$ \\
H. pylori seropositivity & $65-82$ & $265(14.7)$ \\
& negative (Hp-) & $174(9.7)$ \\
& positive (Hp+) & $833(51.9)$ \\
\hline
\end{tabular}


Table 2 Prevalence of antibodies to $H$. pylori proteins by HP serostatus

\begin{tabular}{|c|c|c|c|c|c|c|}
\hline \multirow[b]{2}{*}{ Protein } & \multirow[b]{2}{*}{ Name $^{b}$} & \multirow[b]{2}{*}{ Cut-off [MFI] } & \multicolumn{4}{|c|}{ Seroprevalence (\%) } \\
\hline & & & All $(n=1797)$ & $\mathrm{Hp}^{\mathrm{a}}(n=933)$ & $\mathrm{Hp}^{\mathrm{a}}(n=864)$ & $P^{c}$ \\
\hline HP0547 & CagA & 3091 & 33 & 5 & 63 & $<0.0001$ \\
\hline HP0010 & GroEL & 100 & 47 & 10 & 86 & $<0.0001$ \\
\hline HP1564 & Omp & 342 & 54 & 23 & 88 & $<0.0001$ \\
\hline HP0887 & VacA & 292 & 46 & 12 & 83 & $<0.0001$ \\
\hline HP0305 & HP0305 & 100 & 26 & 2 & 52 & $<0.0001$ \\
\hline HP0410 & HраA & 100 & 25 & 8 & 43 & $<0.0001$ \\
\hline HP0522 & Cag $\delta$ & 107 & 35 & 13 & 60 & $<0.0001$ \\
\hline HP0695 & HyuA & 274 & 27 & 5 & 50 & $<0.0001$ \\
\hline HP1104 & Cad & 100 & 15 & 5 & 26 & $<0.0001$ \\
\hline HP0537 & CagM & 178 & 30 & 7 & 56 & $<0.0001$ \\
\hline HP0875 & Catalase & 487 & 31 & 9 & 56 & $<0.0001$ \\
\hline HP0231 & HP0231 & 100 & 28 & 4 & 53 & $<0.0001$ \\
\hline HP1098 & $\mathrm{HcpC}$ & 158 & 34 & 2 & 69 & $<0.0001$ \\
\hline HP0243 & NapA & 100 & 27 & 5 & 51 & $<0.0001$ \\
\hline HP0073 & UreA & 216 & 33 & 16 & 51 & $<0.0001$ \\
\hline
\end{tabular}

${ }^{a}$ classification of $H$. pylori seropositivity as antibody reactivity with at least 4 antigens; ${ }^{b}$ see Materials and Methods for protein full names; ${ }^{\mathrm{c}}$ Fisher's exact test, comparison of $\mathrm{Hp}$ - and $\mathrm{Hp}+$ sera.

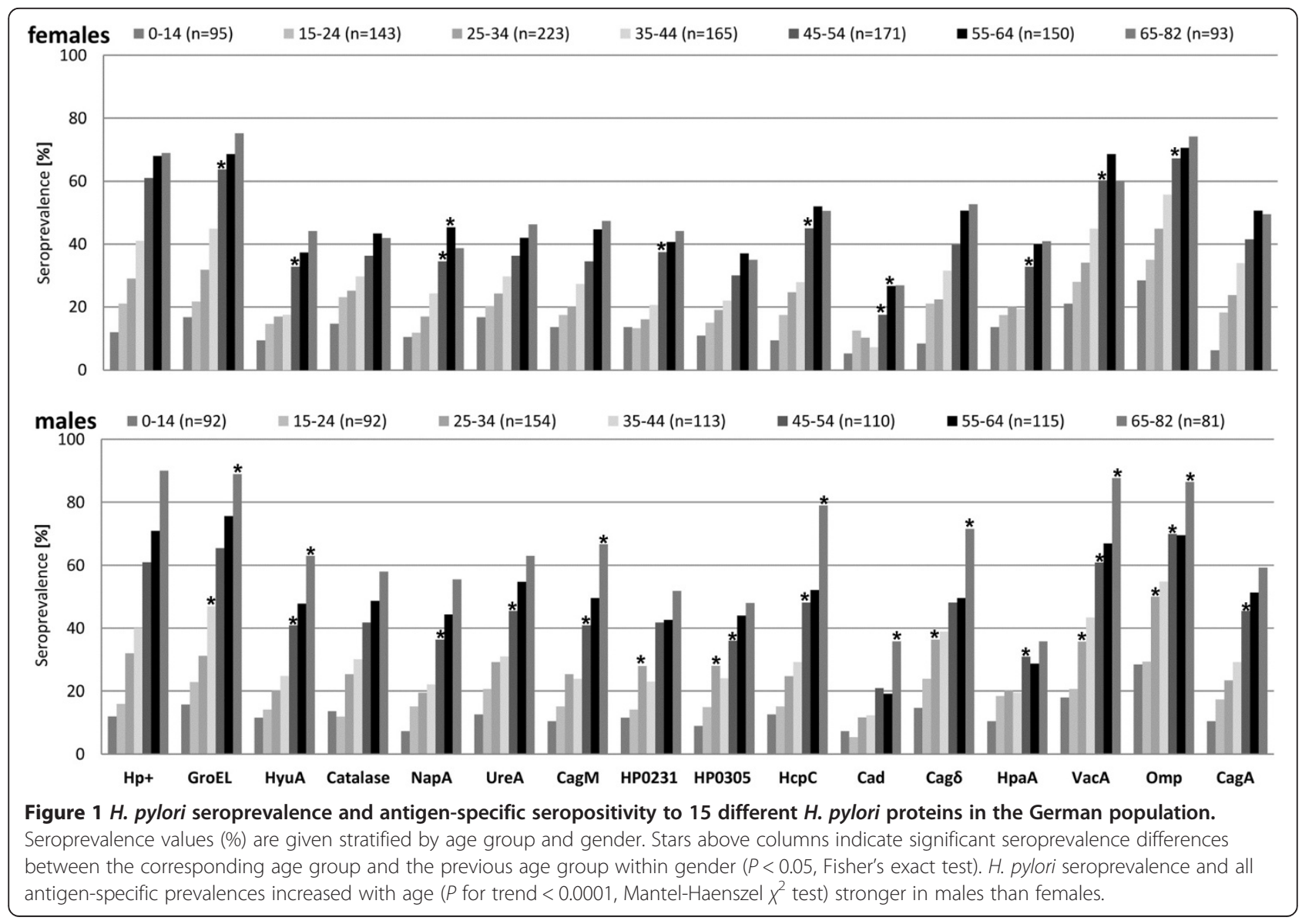


This effect was biggest for GroEL (12.9\% in males) and lowest for Cad (3.4\% in females) (Figure 1).

In the oldest age group, $H$. pylori seroprevalence and prevalences for eleven $H$. pylori proteins (CagA, GroEL, Omp, VacA, Cagס, HyuA, CagM, Catalase, HcpC, NapA and UreA) were significantly higher in males than in females. This was also observed in the age group 35-44 years for HP0231, HP0305 and Cag $\delta$ as well as for UreA (55-64 years). As the only exception significantly higher seroprevalence in females was seen for Catalase in the age group 15-24 years (Figure 1).

\section{Antibody reactivities increase with age among $\mathrm{H}$. pylori seropositives}

Among $\mathrm{Hp}+$ individuals, the antibody responses increased qualitatively and quantitatively with age. H. pylori protein-specific prevalences increased significantly for GroEL, HyuA, Cad, CagM, NapA and UreA in both genders and for Cag $\delta$ in females and for VacA and Catalase in males only (Figure 2). HpaA was the only antigen showing the opposing effect, a decrease from the youngest to the age group 54-65 years but this could be observed in males only (Figure 2).

Reflecting the $H$. pylori protein-specific prevalence increases, multiple seropositivity, i.e. the number of antigens recognized also increased with age for both, males and females (Figure 3). In females, the median number of antigens recognized rose from 7.0 (range 4-12) in the youngest age group to 9.0 (range 4-15) in the oldest age group $(P=0.02)$. While in males, the median started at 8.5 (range 4-13) and rose to 11 (range 5-15) in the oldest age group. The trend over time did not reach significance, but the number of $H$. pylori proteins recognized was overall higher in males than females and differed significantly between gender in the age groups 25-34, 45-54 and 65-82 years (all $P<0.05$, Figure 3).

Antibody reactivity to several individual $H$. pylori proteins also increased with age, for both males and females. This increase was strongest among the $\mathrm{Hp}+$ sera positive for GroEL, HyuA, NapA, CagM, Catalase, or UreA. The median MFI values for these six antigens increased from the youngest to the oldest age group (Figure 4) in males by mean 6.1-fold (SD 3.8) and in females by mean 7.2-fold (SD: 3.6).

\section{Discussion}

Previous serological studies describing $H$. pylori prevalence in a general population relied on crude bacterial lysates as antigens in ELISA. In contrast, our $H$. pylori multiplex serology is based on the detection of antibodies to fifteen affinity-purified $H$. pylori proteins. Definition of $H$. pylori seropositivity is based on antibody reactivity with at least four $H$. pylori proteins. Compared to a conventional combination of screening ELISA and

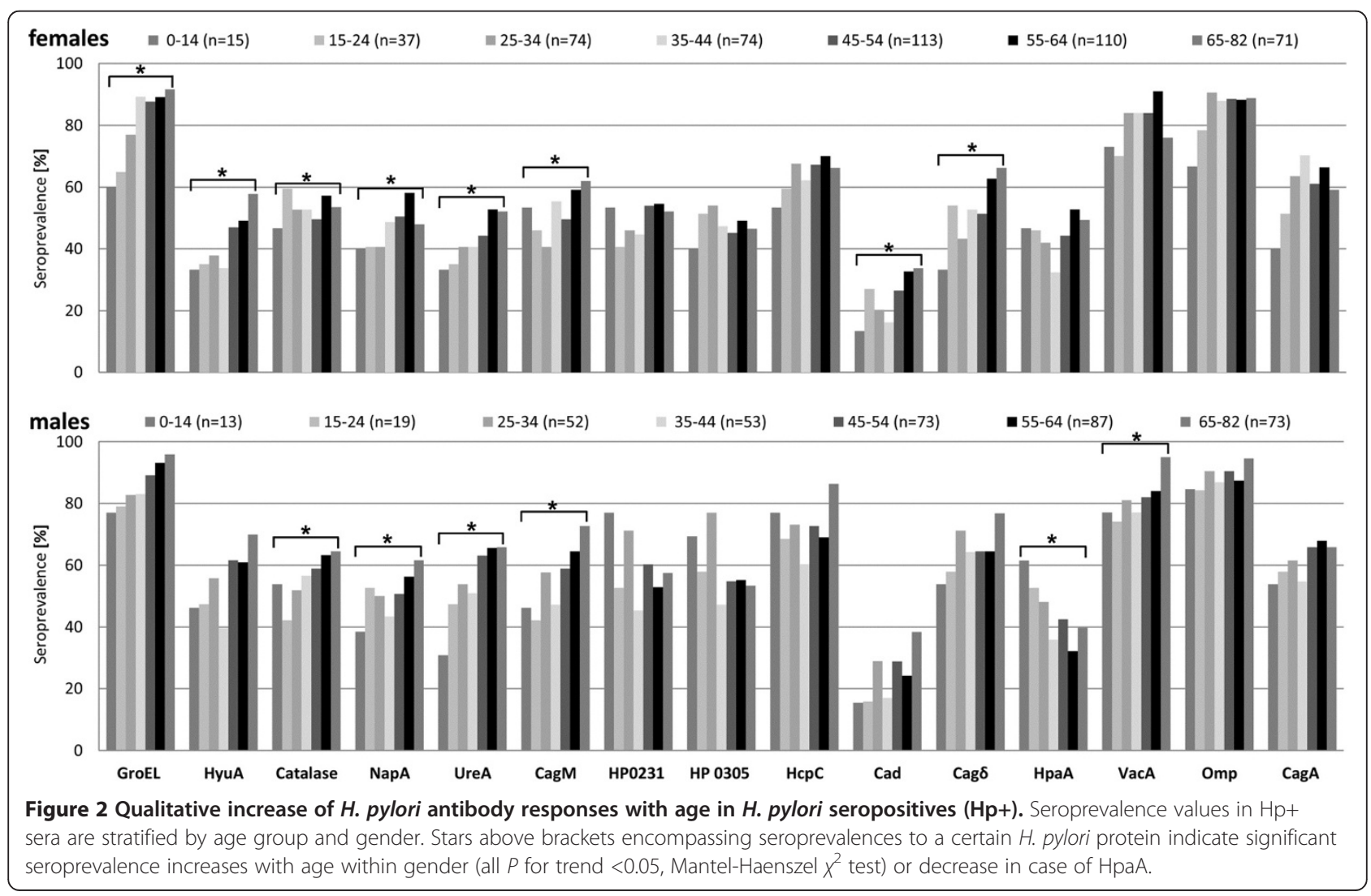




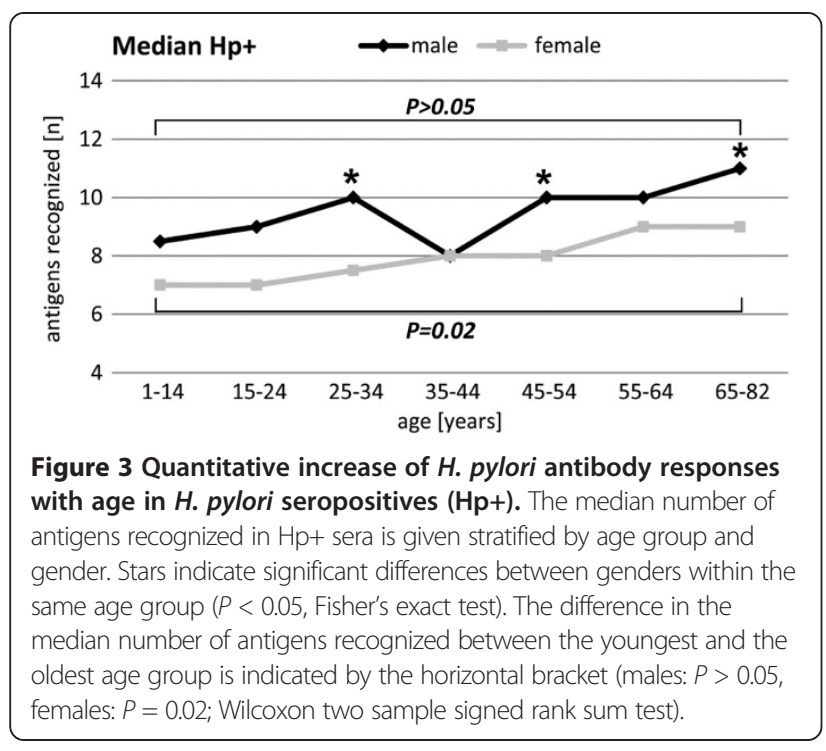

Western blot confirmation multiplex serology has higher specificity without loss of sensitivity [12]. A further strength of multiplex serology is its ability to allow qualitative and quantitative antibody pattern analysis [16].

The 1573 adult subjects (aged 18-82 years) analysed here are representative for the non-institutionalized adult German population [19] concerning age but not gender distribution since sera were an unbiased subset of a population-based study conducted between 1985 and 1989 with a female predominance. Children sera were collected 6 to 17 years later from hospitalised individuals without gastrointestinal disease and their ability to represent the general population is therefore limited. We cannot exclude that the longer storage times and the higher number of freeze-thaw cycles in the sera from adults might have reduced antibody reactivities, however the observed increase from children to adults in number of antigens recognized and in antibody reactivities against the individual antigens is opposite to an reducing effect of longer storage times and more freeze-thaw cycles. The increases with age among adults were observed in samples all originating from the same study with same storage and freeze-thaw cycle history.

We observed an overall $H$. pylori seroprevalence of $48 \%$, $12 \%$ in children $<15$ years and $52 \%$ among adults $>25$ years. Several population-based studies were conducted in industrialized countries between 1982 and 1991. In 4,742 subjects from Northern Ireland (12-64 years) [20], and 2237 subjects from San Marino (23- > 70 years) [21] similar H. pylori prevalences of $50.5 \%$ and $51 \%$, respectively, were reported, in contrast to lower prevalences of 35\% in 3589 Danish adults (30-60 years) [22] and 38\% in 273 Australian adults (20-80 years) [23].

In comparison to other studies from Germany, we observed $72 \%$ of $H$. pylori prevalence for the group 51-61 years which is higher than the $60 \%$ reported for 260 healthy adult German blood donors that were younger and might be healthier than the population analyzed here [24]. However, the $12 \%$ seroprevalence estimated here in children younger than 14 years is comparable to the 13\% described for 216 children from Germany before [25].

H. pylori seroprevalence increased strongly with age, differing by $39 \%$ between the groups of 25-34 and 5564 years of age. Similar age-specific prevalence estimates have been described for other developed countries $[20,22,24,26]$ with the highest prevalence of infection in the older age groups.

The age-dependent differences in seroprevalence are either caused by a birth cohort effect $[27,28]$ due to stronger $H$. pylori exposure in the past decades or by cumulating risk of infection with age. The prevalence of infection depends on the rate of acquisition and loss of infection. The rate of seroconversion is higher in children throughout the world [29-31] although $H$. pylori infection can be acquired at all ages [22,32]. The rate of seroconversion slows down with age in all cohorts $[33,34]$ to small values of $0.2-1.0 \%$ per year estimated as cross sectional prevalence increase per year in adults of developed countries [30] which is slightly lower than a mean prevalence increase of $1.2 \%$ per year estimated here.

The age-dependent increases of seroprevalence were observed also for all $H$. pylori proteins reaching maximum values in males older 65 years. In this oldest age group an extraordinary steep increase in prevalence occurred for the majority of proteins in males that we did not observe in females and that lead to significant gender differences for eleven of the fifteen proteins. Previous meta-analyses also highlight a male predominance of $H$. pylori infection in 18 publications describing adult populations [35] as a global phenomenon, but not for children in ten paediatric populations [36]. In this study none of the proteins seemed to be associated with young age as a marker of childhood infection.

The conserved, surface localized lipoprotein $H$. pylori adhesion $\mathrm{A}(\mathrm{HpaA})$ does not follow the general finding of a seroprevalence increase by age in $H$. pylori seropositives. HpaA seroprevalences significantly decrease with age in males and at least do not increase in females for unknown reasons. We performed analyses stratified by HpaA status (data not shown), and in overall $H$. pylori seropositives. Antibodies to HpaA seem to be a marker for increased immune response, i.e. they are associated with higher seroprevalence to other $H$. pylori proteins and recognition of higher numbers of antigens for both genders. In contrast, HpaA serostatus does not impact seroprevalence for other $H$. pylori proteins in $H$. pylori overall seronegatives. 


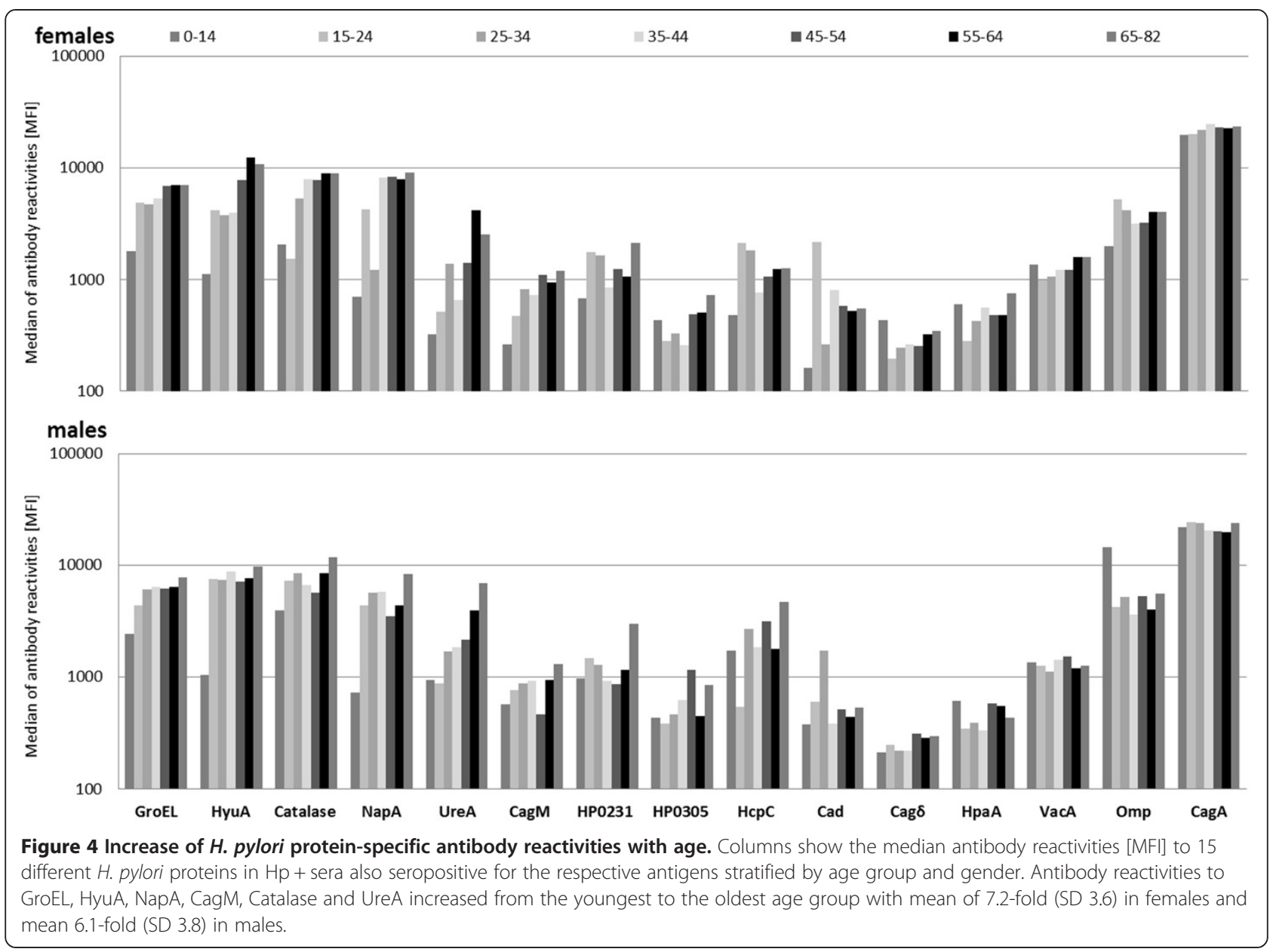

The major finding of our study is the observation of a qualitative increase in the immune response to $H$. pylori with age. The degree of multiple seropositivity and strength of antibody reactivity increased with age among seropositives for GroEL, HyuA, CagM, Catalase, NapA and UreA. These proteins are necessary for bacterial colonization and initiation of the host immune response. GroEL belongs to the chaperone family and promotes refolding of misfolded proteins under stress conditions. It seems to be associated with the adhesion of $H$. pylori to human gastric epithelial cells [37] and the induction of inflammatory responses [38]. NapA also mediates the binding of $H$. pylori to the host cell [39], activates neutrophils and monocytes and antagonizes oxidative stress [40]. Catalase is necessary for long term colonization as part of the antioxidant defence mechanisms of H. pylori [41]. Survival of H. pylori in the acidic gastric habitat is secured by its enzyme urease, composed of the two heterogeneous subunits UreA and UreB, which metabolizes urea to carbon dioxide and ammonia [42]. CagM is necessary for the translocation of the CagA protein into the host cell via the type IV secretion system [43] and HyuA belongs to the oxoprolinase family and is important for aminoacid biosynthesis [44].
This cross-sectional study does not allow distinguishing whether the increase of antibody reactivities is related to age or birth cohort effect. However our observation that this phenomenon also occurs in seropositives provides evidence that it is related to age, and immunosuppression or lower load of $H$. pylori infection in younger people as examples of birth cohort related effects are unlikely. The increase of antibody reactivities with age is opposed to the need of $H$. pylori to escape from the permanent defence of the innate and adaptive immune response. The niche of the gastric mucous layer protects $H$. pylori and makes it inaccessible to specific antibodies and thereby leaves the humoral immune response ineffective [9]. The qualitative increase of antibody reactivities with age might also reflect higher immunogenicity of bacterial antigens in individuals infected with multiple $H$. pylori strains which might be more prevalent in older age groups of the German population. Colonization with multiple $H$. pylori strains is possible [45] and change of strains may occur during chronic infection [46]. H. pylori adapts its genome to its host continuously by point mutation, and intragenomic and intergenomic recombination $[8,11]$. These mechanisms are discussed to be responsible for 
lifelong bacterial immune evasion and development of one's "individual strain". So far, H. pylori multiplex serology is based on antigens conserved among strains and the analysis of strain multiplicity needs to be addressed in a more comprehensive evaluation including antigens that allow for detection of strain specific antibodies.

\section{Conclusion}

The ability of $H$. pylori multiplex serology to simultaneously and quantitatively assess antibody responses to many individual proteins has demonstrated antibody dynamics accumulating with age. This most likely reflects persistent infection and lifelong stimulation of the immune response to $H$. pylori. These findings might help to understand the balance between pathogen and host in asymptomatic individuals and could strengthen future seroepidemiological case-control studies that may allow the identification of disease-associated antibody patterns.

\section{Materials and methods}

\section{Helicobacter pylori multiplex serology}

Detection of antibodies to fifteen $H$. pylori proteins, Cad (cinnamyl-alcohol-dehydrogenase ELI3-2), Cag $\delta$ (cag pathogenicity island protein $\delta$ ), CagM (cag pathogenicity island protein $\mathrm{M}$ ), CagA (cytotoxin-associated antigen A), Catalase, HcpC (conserved hypothetical secreted protein - paralogue HcpA induces IFN $\gamma$ ), HP0231 (hypothetical protein HP0231), HP0305 (hypothetical protein HP0305), HpaA (neuraminyllactose-binding hemagglutinin homolog), HyuA (hydantoin utilization protein A), GroEL (chaperonin GroEL), NapA (neutrophil activating protein (bacterioferritin)), Omp (outer membrane protein), VacA (vacuolating cytotoxin), UreA (urease alpha subunit) was performed by multiplex serology [12]. The method is based on a glutathione S-transferase (GST) capture immunosorbent assay [14,47] in combination with fluorescent-bead technology as described [13]. Recombinant H. pylori proteins from strains 26695 and G27 were expressed in E. coli BL21 Rosetta (Novagen-Merck, Darmstadt, Germany) as double fusion proteins containing an N-terminal GST domain and a C-terminal tag peptide derived from the large $\mathrm{T}$ antigen of simian virus 40. The expression constructs have been described in detail [12]. Recombinant GST-H. pylori-tag fusion proteins from cleared bacterial lysates were loaded on spectrally distinct glutathione-casein-coupled fluorescencelabelled polystyrene beads (SeroMap, Luminex, Austin, Texas) and affinity-purified in a one-step procedure. Sera were diluted 1:50 in a serum pre-incubation buffer containing $1 \mathrm{mg} / \mathrm{ml}$ casein and $2 \mathrm{mg} / \mathrm{ml}$ total lysate protein from bacteria overexpressing GST-tag without intervening $H$. pylori sequences to block binding of antibodies directed against residual bacterial proteins, GST and the tag peptide. To suppress unspecific binding of antibodies to the beads themselves, the serum pre-incubation buffer was supplemented with $0.5 \% \mathrm{w} / \mathrm{v}$ polyvinylalcohol, $0.8 \% \mathrm{w} / \mathrm{v}$ polyvinylpyrrolidone and $2.5 \% \mathrm{v} / \mathrm{v}$ Superchemiblock (Millipore, Billerica, MA, USA) [48]. A monoclonal antibody directed against the $\mathrm{C}$-terminal tag peptide verified the binding of the GST- $H$. pylori-tag fusion proteins to the various beads sets [14]. The differently labelled beads sets loaded with different antigens were mixed and incubated in 96 well plates with an equal volume of the serum dilutions. Antibodies bound to the beads via the GST-H. pylori-tag fusion proteins were stained with biotinylated goat anti-human IgA, IgM, IgG (Dianova, Hamburg, Germany) and the reporter conjugate Rphycoerythrin-labelled streptavidin. A Luminex 100 analyser identified the internal bead colour and thus the antigen carried by the bead. The quantity of bound antibodies was determined as the median reporter fluorescence intensity (MFI) of at least 100 beads per bead set per serum.

\section{Sera}

The 1,797 sera used in this study have been described previously $[19,49,50]$ and contained 1,573 sera from non-institutionalized donors 18 to 82 years of age (median: 41.0 years, 651 males) that were a subset (79\%) of the VERA study ("Verbundstudie Ernährungserhebung und Risikofaktorenanalytik", $n=1,988)$, which is a random subsample of the "Nationale Verzehrstudie" (NVS), a population-based nutrition survey $(n=23,209)$ performed in the West-German population between 1985 and 1989 funded by the Federal Ministry for Research and Technology. Further sera included were from patients of university hospitals in Homburg (Germany) in 2002 ( $n=175$; median age 9, range 2-18; 71 males) and Heidelberg (Germany) collected in 1991 and 1992 ( $n=$ 49; median age 5 , range $1-10 ; 36$ males) excluding patients with gastrointestinal disease. There was no statistically significant difference in the age structure of the 1,797 serum donors and the German standard population $(P=0.70)$.

For analyses of inter-day and inter-plate variation, a quality control (QC) panel of 31 previously characterized [12] sera containing $10 \mathrm{H}$. pylori negative sera (Hp-) and $21 \mathrm{H}$. pylori positive sera $(\mathrm{Hp}+)$ were included in the study.

\section{Assay design, data processing, and cut-off definition}

Loading of glutathione-casein coupled bead sets with their respective antigens was performed in one batch. The loading efficiency was monitored via detection of the C-terminal tag of the respective antigens [14]. MFI values for the different antigens varied less than twofold, indicating similar antigen density on the beads. Correct antigen loading was verified using previously generated data of the QC panel [12]. 
All sera were analysed within three consecutive days, and the QC panel was included each day. Inter-day variation was calculated from the three QC data sets of days 1,2 and 3. Pearson correlation coefficients $\left(R^{2}\right)$ for the individual antigens were calculated from the raw MFI values and ranged from 0.96 to 0.99 (median: 0.98) for day 2 versus day 1 and from 0.88 to 0.99 (median: 0.98) for day 3 versus day 1 . To correct for inter-day variation, the study data of day 2 and day 3 for each antigen were divided by the slopes of the regression lines of the respective QC data pairs. Background corrections have been previously described [12]. For all 15 antigens, antigen-specific cut-off values were applied that were previously determined in a validation study [12] from the MFI values of 20 additional sera negative in Helicobacter-R-Biopharm ELISA as mean plus 3 standard deviations excluding positive outliers [51]. Study data was normalized to this previous validation study by dividing the individual antigen specific antibody reactivity by the slopes of the regression lines of the QC data pairs of day 1 and the previous validation study.

Seropositivity for a given protein was defined as antibody reactivity greater than the antigen-specific cut-off (Table 1). H. pylori seropositivity $(\mathrm{Hp}+)$ was defined as seropositivity for at least four proteins as described previously [12].

\section{Statistical analyses}

Statistical significance of differences in continuous variables, i.e. antibody reactivities (MFI values) and multiple seropositivity (number of antigens recognized) were analysed with the Wilcoxon two sample signed rank sum test. Fisher's Exact test was used to test for differences in dichotomous variables, i.e. H. pylori seropositivity and antibody seroprevalence. Trends in seropositivity with age were estimated with the Mantel-Haenszel $\chi^{2}$ test on one degree of freedom. Seroprevalence increases by age were calculated using linear regression. All tests were performed two-sided. Analyses were performed with SAS software, version 9.1 (SAS Institute Inc). Unadjusted seroprevalence is reported for data stratified by age. $P$-values below 0.05 were considered statistically significant.

\section{Abbreviations}

GST: Glutathione S-transferase; Tag: Undecapeptide from C terminus of SV40 large T-antigen; MFI: Median fluorescence intensity; $\mathrm{Hp}+/-$ : H pylori seropositive/seronegative.

\section{Competing interest}

The authors declare that they have no competing interests.

\section{Authors' contributions}

Conceived and designed the experiments: MP LG. Performed the experiments: AM TW. Analyzed the data: AM TW MP. Contributed reagents/ materials/analysis tools: TW HB LG MP. Wrote the paper: AM, TW, MP. Drafted the article: AM TW MP. Critically revised the article: TW HB LG MP. All authors read and approved the final manuscript.

\section{Acknowledgements}

The authors thank Ute Koch and Monika Oppenländer for excellent technical assistance, Barbara Gärtner (Institute of Virology, Saarland University Hospital, Homburg, Germany) for providing serum samples.

\section{Author details}

${ }^{1}$ Infections and Cancer Epidemiology (F020), Infection and Cancer Program, German Cancer Research Center (DKFZ), Im Neuenheimer Feld 280, Heidelberg 69120, Germany. ${ }^{2}$ Department of Genome Modifications and Carcinogenesis, Infection and Cancer Program, German Cancer Research Center (DKFZ), Im Neuenheimer Feld 280, Heidelberg 69120, Germany. ${ }^{3}$ Department of Epidemiology, German Institute of Human Nutrition (DIFE) Potsdam-Rehbrücke, Arthur Scheunert Strasse 114-116, Nuthetal 14558, Germany.

Received: 13 February 2014 Accepted: 17 April 2014

Published: 26 April 2014

\section{References}

1. Parkin DM: The global health burden of infection-associated cancers in the year 2002. Int J Cancer 2006, 118:3030-3044.

2. Bruce MG, Maaroos HI: Epidemiology of Helicobacter pylori infection. Helicobacter 2008, 13(Suppl 1):1-6.

3. Perez-Perez Gl, Rothenbacher D, Brenner H: Epidemiology of Helicobacter pylori infection. Helicobacter 2004, 9(Suppl 1):1-6.

4. Weyermann M, Rothenbacher D, Brenner H: Acquisition of Helicobacter pylori infection in early childhood: independent contributions of infected mothers, fathers, and siblings. Am J Gastroenterol 2009, 104:182-189.

5. Rowland M, Daly L, Vaughan M, Higgins A, Bourke B, Drumm B: Age-specific incidence of Helicobacter pylori. Gastroenterology 2006, 130:65-72. quiz 211.

6. Fox JG, Wang TC: Inflammation, atrophy, and gastric cancer. J Clin Invest 2007, 117:60-69.

7. Roderick P, Davies R, Raftery J, Crabbe D, Pearce R, Bhandari P, Patel P: The cost-effectiveness of screening for Helicobacter pylori to reduce mortality and morbidity from gastric cancer and peptic ulcer disease: a discrete-event simulation model. Health Technol Assess 2003, 7:1-86.

8. Atherton JC, Blaser MJ: Coadaptation of Helicobacter pylori and humans: ancient history, modern implications. J Clin Invest 2009, 119:2475-2487.

9. Portal-Celhay C, Perez-Perez Gl: Immune responses to Helicobacter pylori colonization: mechanisms and clinical outcomes. Clin Sci (Lond) 2006, 110:305-314.

10. van Amsterdam $\mathrm{K}$, van Viet $A \mathrm{H}$, Kusters JG, van der Ende A: Of microbe and man: determinants of Helicobacter pylori-related diseases. FEMS Microbiol Rev 2006, 30:131-156.

11. Baltrus DA, Blaser MJ, Guillemin K: Helicobacter pylori Genome Plasticity. Genome Dyn 2009, 6:75-90

12. Michel A, Waterboer T, Kist M, Pawlita M: Helicobacter pylori multiplex serology. Helicobacter 2009, 14:525-535.

13. Waterboer T, Sehr P, Michael KM, Franceschi S, Nieland JD, Joos TO, Templin MF, Pawlita M: Multiplex human papillomavirus serology based on in situ-purified glutathione s-transferase fusion proteins. Clin Chem 2005, 51:1845-1853.

14. Sehr P, Zumbach K, Pawlita M: A generic capture ELISA for recombinant proteins fused to glutathione S-transferase: validation for HPV serology. $\mathrm{J}$ Immunol Methods 2001, 253:153-162.

15. Gao L, Weck MN, Michel A, Pawlita M, Brenner H: Association between chronic atrophic gastritis and serum antibodies to 15 Helicobacter pylori proteins measured by multiplex serology. Cancer Res 2009, 69:2973-2980.

16. Gao L, Michel A, Weck MN, Arndt V, Pawlita M, Brenner H: Helicobacter pylori infection and gastric cancer risk: evaluation of $15 \mathrm{H}$. pylori proteins determined by novel multiplex serology. Cancer Res 2009 69:6164-6170

17. Song H, Michel A, Nyren O, Ekstrom AM, Pawlita M, Ye W: A CagA-independent cluster of antigens related to the risk of noncardia gastric cancer: Associations between Helicobacter pylori antibodies and gastric adenocarcinoma explored by multiplex serology. Int J Cancer 2013, 12:2942-2950

18. Epplein M, Zheng W, Xiang YB, Peek RM Jr, Li H, Correa P, Gao J, Michel A, Pawlita M, Cai Q, Shu XO: Prospective study of Helicobacter pylori biomarkers for gastric cancer risk among Chinese men. Cancer Epidemiol Biomarkers Prev 2012, 21:2185-2192 
19. Michael KM, Waterboer T, Sehr P, Rother A, Reidel U, Boeing H, Bravo IG, Schlehofer J, Gartner BC, Pawlita M: Seroprevalence of 34 human papillomavirus types in the German general population. PLOS Pathog 2008, 4:e1000091.

20. Murray LJ, McCrum EE, Evans AE, Bamford KB: Epidemiology of Helicobacter pylori infection among 4742 randomly selected subjects from Northern Ireland. Int J Epidemiol 1997, 26:880-887.

21. Gasbarrini G, Pretolani S, Bonvicini F, Gatto MR, Tonelli E, Megraud F, Mayo K, Ghironzi G, Giulianelli G, Grassi M: A population based study of Helicobacter pylori infection in a European country: the San Marino Study. Relations with gastrointestinal diseases. Gut 1995, 36:838-844

22. Andersen LP, Rosenstock SJ, Bonnevie O, Jorgensen T: Seroprevalence of immunoglobulin $\mathrm{G}, \mathrm{M}$, and $\mathrm{A}$ antibodies to Helicobacter pylori in an unselected Danish population. Am J Epidemiol 1996, 143:1157-1164.

23. Lin SK, Lambert JR, Nicholson L, Lukito W, Wahlqvist M: Prevalence of Helicobacter pylori in a representative Anglo-Celtic population of urban Melbourne. J Gastroenterol Hepatol 1998, 13:505-510.

24. Breuer T, Sudhop T, Hoch J, Sauerbruch T, Malfertheiner P: Prevalence of and risk factors for Helicobacter pylori infection in the western part of Germany. Eur J Gastroenterol Hepatol 1996, 8:47-52.

25. Hornemann F, Nilius M, Malfertheiner P, Bartmann P: Seroprevalence of Helicobacter pylori in German infants and children. Helicobacter 1997, 2:176-179.

26. Moujaber T, Maclntyre CR, Backhouse J, Gidding H, Quinn H, Gilbert GL: The seroepidemiology of Helicobacter pylori infection in Australia. Int J Infect Dis 2008, 12:500-504.

27. Cullen DJ, Collins BJ, Christiansen KJ, Epis J, Warren JR, Surveyor I, Cullen K. When is Helicobacter pylori infection acquired? Gut 1993, 34:1681-1682.

28. Banatvala N, Mayo K, Megraud F, Jennings R, Deeks JJ, Feldman RA: The cohort effect and Helicobacter pylori. J Infect Dis 1993, 168:219-221.

29. Parsonnet J: The incidence of Helicobacter pylori infection. Aliment Pharmacol Ther 1995, 9(Suppl 2):45-51.

30. Brown LM: Helicobacter pylori: epidemiology and routes of transmission. Epidemiol Rev 2000, 22:283-297.

31. Mitchell HM, Li YY, Hu PJ, Liu Q, Chen M, Du GG, Wang ZJ, Lee A, Hazell SL: Epidemiology of Helicobacter pylori in southern China: identification of early childhood as the critical period for acquisition. J Infect Dis 1992, 166:149-153.

32. Halitim F, Vincent $P$, Michaud L, Kalach N, Guimber D, Boman F, Turck D, Gottrand F: High rate of Helicobacter pylori reinfection in children and adolescents. Helicobacter 2006, 11:168-172.

33. Sipponen P, Kosunen TU, Samloff IM, Heinonen OP, Siurala M: Rate of Helicobacter pylori acquisition among Finnish adults: a fifteen year follow-up. Scand J Gastroenterol 1996, 31:229-232.

34. Malaty HM, El-Kasabany A, Graham DY, Miller CC, Reddy SG, Srinivasan SR, Yamaoka Y, Berenson GS: Age at acquisition of Helicobacter pylori infection: a follow-up study from infancy to adulthood. Lancet 2002, 359:931-935.

35. Replogle ML, Glaser SL, Hiatt RA, Parsonnet J: Biologic sex as a risk factor for Helicobacter pylori infection in healthy young adults. Am J Epidemiol 1995, 142:856-863.

36. de Martel C, Parsonnet J: Helicobacter pylori infection and gender: a meta-analysis of population-based prevalence surveys. Dig Dis Sci 2006, 51:2292-2301.

37. Yamaguchi H, Osaki T, Kurihara N, Taguchi H, Hanawa T, Yamamoto T, Kamiya S: Heat-shock protein 60 homologue of Helicobacter pylori is associated with adhesion of $\mathrm{H}$. pylori to human gastric epithelial cells. J Med Microbiol 1997, 46:825-831.

38. Takenaka R, Yokota K, Ayada K, Mizuno M, Zhao Y, Fujinami Y, Lin SN, Toyokawa T, Okada H, Shiratori Y, Oguma K: Helicobacter pylori heat-shock protein 60 induces inflammatory responses through the Toll-like receptor-triggered pathway in cultured human gastric epithelial cells. Microbiology 2004, 150:3913-3922.

39. Namavar F, Sparrius M, Veerman EC, Appelmelk BJ, Vandenbroucke-Grauls CM: Neutrophil-activating protein mediates adhesion of Helicobacter pylori to sulfated carbohydrates on high-molecular-weight salivary mucin. Infect Immun 1998, 66:444-447.

40. Wang G, Hong Y, Olczak A, Maier SE, Maier RJ: Dual Roles of Helicobacter pylori NapA in inducing and combating oxidative stress. Infect Immun 2006, 74:6839-6846.

41. Harris AG, Wilson JE, Danon SJ, Dixon MF, Donegan K, Hazell SL: Catalase (KatA) and KatA-associated protein (KapA) are essential to persistent colonization in the Helicobacter pylori SS1 mouse model. Microbiology 2003, 149:665-672.

42. Kavermann H, Burns BP, Angermuller K, Odenbreit S, Fischer W, Melchers $K$, Haas R: Identification and characterization of Helicobacter pylori genes essential for gastric colonization. J Exp Med 2003, 197:813-822.

43. Fischer W, Puls J, Buhrdorf R, Gebert B, Odenbreit S, Haas R: Systematic mutagenesis of the Helicobacter pylori cag pathogenicity island: essential genes for CagA translocation in host cells and induction of interleukin-8. Mol Microbiol 2001, 42:1337-1348.

44. Krah A, Miehlke S, Pleissner KP, Zimny-Arndt U, Kirsch C, Lehn N, Meyer TF, Jungblut PR, Aebischer T: Identification of candidate antigens for serologic detection of Helicobacter pylori-infected patients with gastric carcinoma. Int J Cancer 2004, 108:456-463.

45. Taylor NS, Fox JG, Akopyants NS, Berg DE, Thompson N, Shames B, Yan L, Fontham E, Janney F, Hunter FM, Correa P: Long-term colonization with single and multiple strains of Helicobacter pylori assessed by DNA fingerprinting. J Clin Microbiol 1995, 33:918-923.

46. Kuipers EJ, Israel DA, Kusters JG, Gerrits MM, Weel J, van Der Ende A, van Der Hulst RW, Wirth HP, Hook-Nikanne J, Thompson SA, Blaser MJ: Quasispecies development of Helicobacter pylori observed in paired isolates obtained years apart from the same host. J Infect Dis 2000, 181:273-282.

47. Sehr P, Muller M, Hopfl R, Widschwendter A, Pawlita M: HPV antibody detection by ELISA with capsid protein L1 fused to glutathione S-transferase. J Virol Methods 2002, 106:61-70.

48. Waterboer T, Sehr P, Pawlita M: Suppression of non-specific binding in serological Luminex assays. J Immunol Methods 2006, 309:200-204.

49. Hepp KD: Food consumption habits in Germany-the clinician's point of view. Metabolism 1995, 44:14-17.

50. Heseker H, Hartmann S, Kubler W, Schneider R: An epidemiologic study of food consumption habits in Germany. Metabolism 1995, 44:10-13.

51. Muller M, Viscidi RP, Sun Y, Guerrero E, Hill PM, Shah F, Bosch FX, Munoz N, Gissmann L, Shah KV: Antibodies to HPV-16 E6 and E7 proteins as markers for HPV-16-associated invasive cervical cancer. Virology 1992, 187:508-514.

doi:10.1186/1757-4749-6-10

Cite this article as: Michel et al.: Helicobacter pylori antibody patterns in Germany: a cross-sectional population study. Gut Pathogens 2014 6:10.

\section{Submit your next manuscript to BioMed Central and take full advantage of:}

- Convenient online submission

- Thorough peer review

- No space constraints or color figure charges

- Immediate publication on acceptance

- Inclusion in PubMed, CAS, Scopus and Google Scholar

- Research which is freely available for redistribution

Submit your manuscript at www.biomedcentral.com/submit
C Biomed Central 